\title{
ANALISIS SISTEM PERAWATAN PADA MESIN KMF 250 A MENGGUNAKAN METODE OVERALL EQUIPMENT EFFECTIVENESS (OEE) DI PT TSG
}

\author{
${ }^{1} \cdot$ Hermanto, ${ }^{2}$ Sahat Sinambela, ${ }^{3}$ Elfitria Wiratman \\ ${ }^{1,2,3}$ Program Studi Teknik Industri FTMIPA \\ Universitas Indraprasta PGRI Jakarta \\ Nangka No 58c /TB. Simatupang Tanjung Barat- Jagakarsa- Jakarta Selatan 12530 \\ Email : hers3sm@gmail.com / hermanto_trisakti@yahoo.co.id
}

\begin{abstract}
A b s trak
Tujuan dari penelitian ini adalah meningkatkan efektifitas mesin $K M F 250$ A melalui 3 (tiga) rasio perhitungan OEE (availability, performance, quality) dan mengidentifikasi akar penyebab rendahnya pencapaian rasio OEE yang di pengaruhi dengan system perawatan dan berdampak pada efektifitas mesin KMF $250 \mathrm{~A}$. Selain itu penulis berharap agar hasil analisa lebih baik dari kondisi awal. Metode penelitian yang penulis gunakan adalah deskriptif analisis, yaitu menggambarkan ketersediaan, kinerja, dan kualitas produksi mesin KMF $250 \mathrm{~A}$ berdasarkan data dan informasi yang sebenarnya dengan mengumpulkan, menyusun, mengklasifikasikan dan menganalisis khususnya informasi dan data-data mengenai efektifitas mesin KMF 250 A. Hasil perhitungan yang diperoleh dari rata-rata nilai OEE adalah 75,69\% yang terdiri dari 3 (tiga) rasio antara lain availability rate $89,43 \%$, performance efficiency $88,39 \%$, quality rate $95,77 \%$. Hasil pengukuran masing-masing losses yaitu equipment failure $28,62 \%$, setup and adjustment $6,61 \%$, idle dan minor stoppage 2,69\%, reduced speed $9,32 \%$, defect losses $7,57 \%$, reduced yield $0.16 \%$. Dari ketiga rasio OEE yang mempengaruhi rendahnya kinerja mesin KMF $250 \mathrm{~A}$ adalah performance efficiency sebesar $88,39 \%$. Sedangkan jenis kerugian terbesar pada equipment failure sebesar 28,62\%.
\end{abstract}

Kata Kunci : Efektifitas Mesin KMF 250 A, Overall Equipment Effectivenees, Sistem Perawatan

\section{PENDAHULUAN}

PT TANSRIGANI sebagai salah satu perusahaan yang bergerak dibidang manufacture injection plastik yang berdiri sejak tahun 1982 yang memproduksi produk Container Packaging (CP) berbahan utama plastik, sebagian besar produk tersebut di pasarkan untuk perusahaanperusahaan pembuatan cat maupun perusahaan makanan berkaleng. Dengan mesin injection plastik molding yang sudah memiliki usia pemakaian cukup lama, mesin-mesin di PT TANSRIGANI sering mengalami breakdown mesin yang tinggi dan waktu setup yang tidak standar. Hal ini menghambat jalannya proses produksi yang berdampak pada penurunan kapasitas produksi. Pada saat dilakukan penelitian, PT TANSRIGANI menerapkan sistem perawatan corrective maintenance, yaitu melakukan perbaikan ketika terdapat kerusakan. Namun juga dibantu dengan planned maintenance dimana di jadwalkan setiap 24 bulan sekali untuk dilakukan perbaikan preventive maintenance.

Kapasitas Produksi PT TANSRIGANI perbulan nya mencapai 250.000 unit Container Packaging (CP), dengan tingginya kapasitas produksi ada beberapa mesin sering mengalami downtime yang tinggi salah satunya yaitu mesin injection Krauss Maffei (KMF) 250 A yang memproduksi Lids (tutup) 20 Liter Multiseal. Overall Equipment Effectiveness (OEE) merupakan ukuran parameter mesin untuk mengetahui seberapa besar kinerja suatu mesin, semakin tinggi nilai Overall Equipment Effectiveness (OEE) maka semakin baik kinerja mesin, sedangkan semakin rendah nilai Overall Equipment Effectiveness (OEE) maka semakin buruk kinerja mesin. Untuk meningkatkan nilai Overall Equipment Effectiveness (OEE) pada mesin KMF 250 A dibutuhkan metode yang tepat seperti fishbone. Perusahaan melakukan analisis penyebab menurunnya nilai Overall Equipment Effectiveness (OEE) pada 4 faktor yang dianggap mempunyai keterkaitan yang 
sangat kuat terhadap permasalahan yang terjadi yaitu faktor waktu set up mesin, faktor waktu perbaikan mesin, faktor material, dan faktor prosedur kerja.

\section{METODE PENELITIAN}

\section{a. Metode Penelitian}

Metode penelitian yang digunakan menggunakan Overall equipment effectiveness (OEE). Metode Overall equipment effectiveness (OEE) digunakan sebagai pengukuran produktivitas produksi di mesin KMF 250 A. Faktor-faktor yang diidentifikasi meliputi tingkat efektivitas waktu, kinerja mesin, serta kualitas produk yang dihasilka. Selanjutnya, nilai Overall equipment effectiveness (OEE) dan faktor-faktor yang mempengaruhi akan dievaluasi dengan membandingkan dengan standar yang ada. Hasil identifikasi dan evaluasi produktivitas dengan berbagai faktor yang mempengaruhi berdasarkan metode Overall equipment effectiveness (OEE) akan dilakukan perencanaan formulasi model peningkatan produktivitas dilakukan untuk menghasilkan perencanaan produktivitas kedepannya.

\section{b. Teknik Analisa Data}

Analisi dilakukan pada hasil perhitungan :

1. Perhitungan Availability

Availability adalah rasio waktu operation time terhadap loading time-nya

2. Perhitungan Performance Efficiency adalah rasio kualitas produk yang dihasilkan dikalikan dengan waktu siklus idealnya terhadap waktu yang tersedia untuk melaukan proses produksi (Operation Time).

3. Perhitungan Rate Of Quality Produk dalah rasio produk yang baik (good product) yang sesuai dengan sepesifikasi produk yang telah ditentukan terhadap jumlah produk yang diproses.

4. Perhitungan Overall Equipment Effectiveness (OEE) Setelah nilai availability, performance efficiency dan rate of quality product pada mesin KMF 250 A diperoleh maka dilakukan perhitungan nilai overall equipmwnt effectiveness (OEE) untuk mengetahui besarnya efektifitas pengguna mesin.

5. Perhitungan Six Big Losses

Setelah mendapatkan nilai Overall Equipment Effectiveness (OEE) maka dilakukan analisa penyabab masalah dari nilai tersebut dengan menghitung nilai enam kesalahan terbesar dengan data downtime mesin KMF $250 \mathrm{~A}$.

\section{HASIL DAN PEMBAHASAN}

\section{A. Pengolahan Data}

Dalam pengolahan data, hal pertama yang dilakukan adalah pengukuran terhadap nilai Overall Equipment Effectiveness (OEE) untuk mesin injeksi plastik. Yang mana nilai OEE tergantung dari tiga ratio utama, yaitu : Availability, Performance, dan Quality. Untuk itu nilai dari ketiga ratio tersebut harus terlebih dulu diperoleh. Setelah kita mendapatkan nilai OEE yang kita inginkan, maka dapat dilakukan pengolahan data terhadap kerugian - kerugian. Sehingga kita akan dapat melihat hubungan dari kerugian tersebut terhadap nilai OEE selama periode Januari 2017 sampai dengan Maret 2017. Untuk itu dalam pengolahan data ini terdiri dari 4 langkah yaitu:

1. Mengukur nilai OEE bulan Januari 2017 sampai dengan Maret 2017

2. Mencari hubungan antara nilai OEE terhadap losses peralatan / mesin injeksi.

3. Mencari penyebab masalah yang berkaitan dengan nilai OEE sehingga bisa meningkatkan nilai OEE sesuai dengan standard yang ditentukan.

4. Mengukur kembali nilai OEE bulan April 2017 dan Mei 2017

Langkah ketiga sangatlah berkaitan dengan hasil analisis terhadap dua langkah sebelumnya, oleh karenanya langkah ketiga ini akan diuraikan di bagian analisis.

Pengukuran OEE ini dilakukan di salah satu mesin produksi di PT Tansri Gani. Pada saat melakukan penelitian, mesin injeksi plastik ini merupakan mesin yang memproduksi Tutup (Lids) 20 Liter Multiseal, dimana prosesnya adalah proses injeksi plastik. Sebagaimana telah diuraikan pada latar belakang, pemilihan mesin injeksi ini karena merupakan mesin injeksi yang memiliki performance yang sangat rendah dibandingkan dengan mesin - mesin injeksi yang lainnya.

JIM, Vol. 3, No. 1, Januari 2018, pp.29-36 
Melalui penelitian ini, kami mencoba memberikan masukan terhadap permasalahan yang terjadi dari segi penggunaan peralatan tersebut menggunakan.

\section{Pengukuran Nilai Availability Ratio}

Nilai Avaibility bulan Januari 2017 s/d Maret 2017 dapat dilihat pada tabel dibawah ini :

Tabel 1. Avaibility mesin KMF 250 A bulan Januari s/d Maret 2017

\begin{tabular}{|c|c|c|c|}
\hline \multicolumn{4}{|c|}{ Avaibility Rate } \\
\hline Bulan & $\begin{array}{c}\text { Operating Time } \\
\text { (Menit) }\end{array}$ & $\begin{array}{c}\text { Total Downtime } \\
\text { (Menit) }\end{array}$ & Avaibility $(\%)$ \\
\hline Januari & 34740 & 2820 & $91.88 \%$ \\
\hline Februari & 31920 & 3900 & $87.78 \%$ \\
\hline Maret & 30600 & 8340 & $72.75 \%$ \\
\hline \multicolumn{3}{|c|}{ Rata-Rata } & $84.14 \%$ \\
\hline \multicolumn{4}{|l|}{ Keterangan : } \\
\hline \multicolumn{3}{|c|}{ Operating Time : W aktu Oprasional Mesin. } & \\
\hline \multicolumn{4}{|c|}{ Total Donwtime : Waktu Set Up+Breakdown. } \\
\hline
\end{tabular}

2. Perhitungan Nilai Performance Efficiency

Tabel 2. Performance Effisiency Rate Mesin KMF250 A Bulan Januari s/d Maret

\begin{tabular}{|c|c|c|c|c|}
\hline Bulan & $\begin{array}{c}\text { Total Product } \\
\text { Processed (Pss) }\end{array}$ & $\begin{array}{c}\text { Cycle Time } \\
\text { (Detik/ / pes) }\end{array}$ & $\begin{array}{c}\text { Operating } \\
\text { Time (Menit) }\end{array}$ & $\begin{array}{c}\text { Performance } \\
\text { Effisiency (\%) }\end{array}$ \\
\hline Januari & 63,545 & 32 & 1915200 & $94.19 \%$ \\
\hline Februari & 58,389 & 32 & 1681200 & $89.98 \%$ \\
\hline Maret & 55,975 & 32 & 1335600 & $74.56 \%$ \\
\hline \multicolumn{5}{|c|}{ Rata-Rata } \\
\hline
\end{tabular}

3. Perhitungan Rate of Quality

Tabel 3. Hasil Produksi Dan Total Scrap

\begin{tabular}{|c|c|c|}
\hline Bulan & $\begin{array}{c}\text { Total Product } \\
\text { Processed (Pcs) }\end{array}$ & Total Scrap(Pcs) \\
\hline Januari & 63,545 & 2,005 \\
\hline Februari & 58,389 & 1,889 \\
\hline Maret & 55,975 & 1,455 \\
\hline
\end{tabular}

Sumber: PT. TGS

Untuk menghitung nilai rate of quality product digunakan rumusan sebagai berikut : rate of quality product $=(($ processed amount - defect amount $) /$ processed amount $) \times 100$.

Tabel 4. Rate of Quality Product Mesin KMF 250 A Bulan Januari s/d Maret 2017

\begin{tabular}{|c|c|c|c|}
\hline Bulan & $\begin{array}{c}\text { Total Product } \\
\text { Processed (Pcs) }\end{array}$ & Total Scrap(Pcs) & Rate of Quality Product (\%) \\
\hline Januari & 63,545 & 2,005 & $96.84 \%$ \\
\hline Februari & 58,389 & 1,889 & $96.76 \%$ \\
\hline Maret & 55,975 & 1,455 & $97.40 \%$ \\
\hline \multicolumn{3}{|c|}{ rata-rata } & $97.00 \%$ \\
\hline
\end{tabular}




\section{Perhitungan overall equipment effectivenes $(\mathrm{OEE})$}

Perhitungan OEE adalah perkalian nilai-nilai avaibility, performance efficiency dan rate of quality product yang sudah diperoleh.

$$
O E E=\text { Availability } x \text { performance } x \text { Quality Rate }
$$

Tabel 5 Nilai $O E E$ Mesin $K M F 250$ A Bulan Januari s/d Maret

\begin{tabular}{|c|c|c|c|c|}
\hline \multirow{2}{*}{ Keterangan } & \multicolumn{3}{|c|}{ Bulan } & \multirow{2}{*}{ Rata:Ratit } \\
\hline & Jamain' & Febonalain & Maret & \\
\hline Avabibility Rate $\left(\%_{0}\right)$ & $91.88 \%$ & $87,78 \%$ & $72.75 \%$ & $84.14 \%$ \\
\hline Performance $(\%)$ & $94.19 \%$ & $89,98 \%$ & $74.56 \%$ & $86.24 \%$ \\
\hline Oudiliv Rate $\left(y_{0}\right)$ & $90.814 \%$ & $96.76 \%$ & $97.40 \%$ & 97,00\% \\
\hline Overall Equipment Effectiveness ( $/ \%)$ & $83.81 \%$ & $76,43 \%$ & $52.83 \%$ & $7039 \%$ \\
\hline
\end{tabular}

5. Perhitungan nilai availability, performance efficiency, rate of quality dan overall equipment effectivenes (OEE) mesin KMF 250 A untuk bulan April 2017 sampai dengan Mei 2017

Tabel 6 Nilai overall equipment effectivenes (OEE) Bulan April s/d Mei Mesin KMF 250

\begin{tabular}{|c|c|c|}
\hline \multirow{2}{*}{ Keterangan } & \multicolumn{2}{|c|}{ Bulan } \\
\cline { 2 - 3 } & April & Mei \\
\hline Quality Rate (\%) & $97.02 \%$ & $97.71 \%$ \\
\hline Avaibility Rate (\%) & $89.87 \%$ & $93.33 \%$ \\
\hline Performance (\%) & $92.18 \%$ & $95.65 \%$ \\
\hline OEE (\%) & $\mathbf{8 0 . 3 6 \%}$ & $\mathbf{8 7 . 2 3 \%}$ \\
\hline
\end{tabular}

\section{B. Pembahasan dan Analisis}

Pembahasan dan analisa nilai overall equipment effectivenes (OEE) yang meliputi nilai availability, nilai performance efficiency, nilai rate of quality dan nilai overall equipment effectivenes $(O E E)$ yang diuraikan sebagai berikut :

\section{a. Pembahasan dan Analisi Nilai Availability}

Pada Gambar 4.5 merupakan perbandingan nilai avaliability saat sebelum perbaikan pada bulan Juli 2016 sampai dengan Desember 2016 dan sesudah dilakukan perbaikan selama 5 bulan pada bulan Januari 2017 sampai dengan Mei 2017

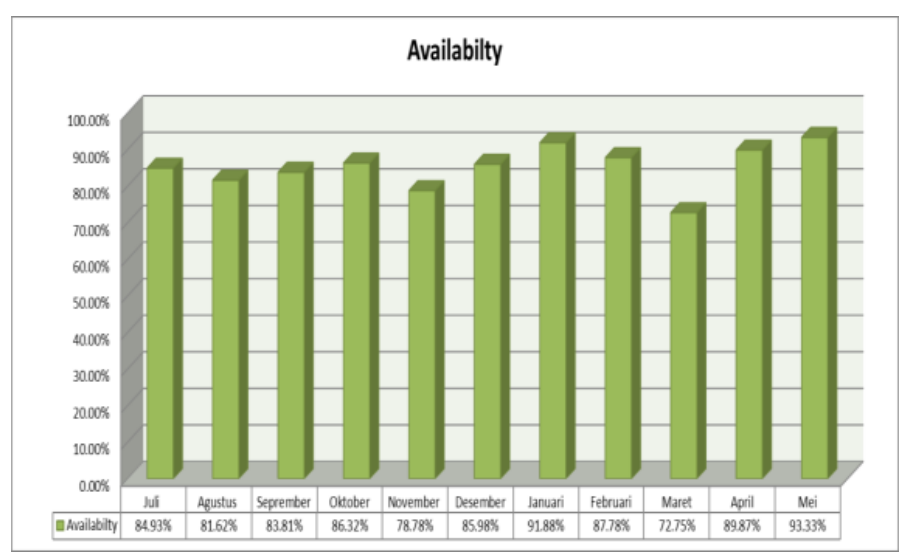

Gambar 1. Data Percentage Perbandingan Nilai Avaliability 
Dilihat dari standar nilai availability untuk mencapai nilai overall equipment effectivenes $(O E E)$ diatas angka 85\% maka nilai availability minimal sebesar $90 \%$, maka dapat disimpulkan bahwa nilai availability mesin KMF 250 A masih dibawah nilai standar dengan selisih nilai tidak terlalu jauh yaitu sebesar $2,88 \%$.

\section{b. Pembahasan Nilai Performance Efficiency}

Analisa performance efficiency merupakan ratio kecepatan operasi aktual dari peralatan dengan kecepatan ideal berdasarkan kapasitas produksi. Dengan membandingkan waktu siklus aktual terhadap waktu siklus yang ideal. Berikut adalah hasil perbandingan nilai performance saat sebelum perbaikan pada bulan Juli 2016 sampai dengan Desember 2016 dan sesudah dilakukan perbaikan selama 5 bulan pada bulan Januari 2017 sampai dengan 2017.

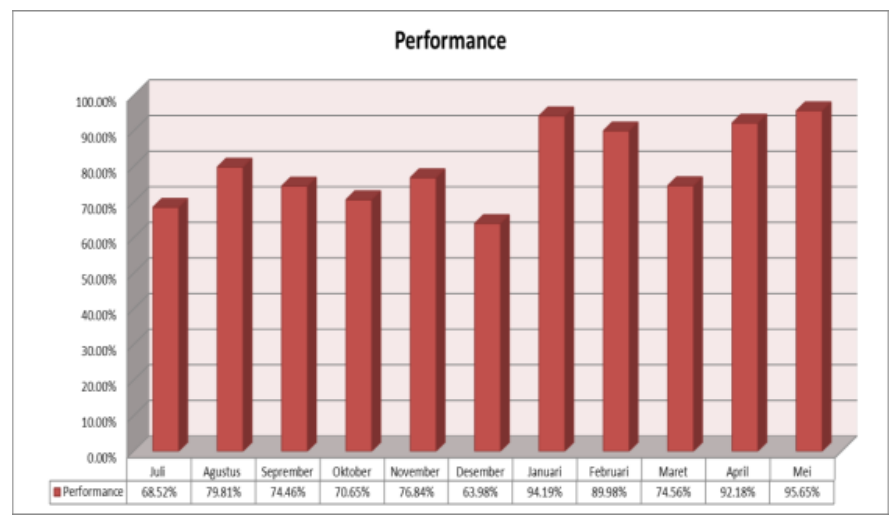

Gambar 2. Data Percentage Perbandingan Nilai Performance

Dilihat dari standar nilai performance untuk mencapai nilai overall equipment effectivenes (OEE) diatas angka $85 \%$ maka nilai performance minimal sebesar $95 \%$, maka dapat disimpulkan bahwa nilai performance mesin KMF 250 A masih dibawah nilai standar dengan selisih nilai sebesar 7,88\%.

\section{c. Pembahasan Nilai Rate Of Quality}

Berikut adalah hasil perbandingan nilai rate of quality saat sebelum perbaikan pada bulan Juli 2016 sampai dengan Desember 2016 dan sesudah dilakukan perbaikan selama 5 bulan pada bulan Januari 2017 sampai dengan 2017.

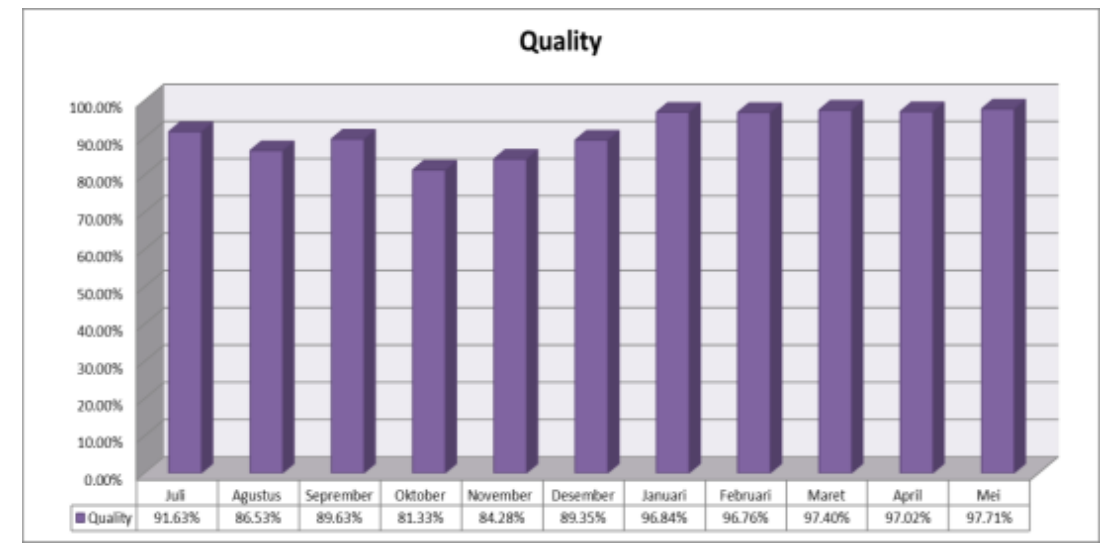

Gambar 3. Data Precentage Perbandingan Nilai Rate Of Quality

Dilihat dari standar nilai rate of quality untuk mencapai nilai overall equipment effectivenes $(O E E)$ diatas angka $85 \%$ maka nilai rate of quality minimal sebesar $99 \%$, maka dapat disimpulkan bahwa nilai rate of quality mesin KMF 250 A masih dibawah nilai standar dengan selisih tidak terlalu jauh dengan nilai sebesar $1,85 \%$.

\section{Pembahasan Nilai Overall Equipment Effectivenes $(\mathrm{OEE})$}

Nilai overall equipment effectivenes (OEE) sangat dipengaruhi oleh nilai avaibilitas, performance efficiency dan rate of quality yang didapat. Berikut adalah hasil perbandingan nilai 
rate of quality saat sebelum perbaikan pada bulan Juli 2016 sampai dengan Desember 2016 dan sesudah dilakukan perbaikan selama 5 bulan pada bulan Januari 2017 sampai dengan 2017 .

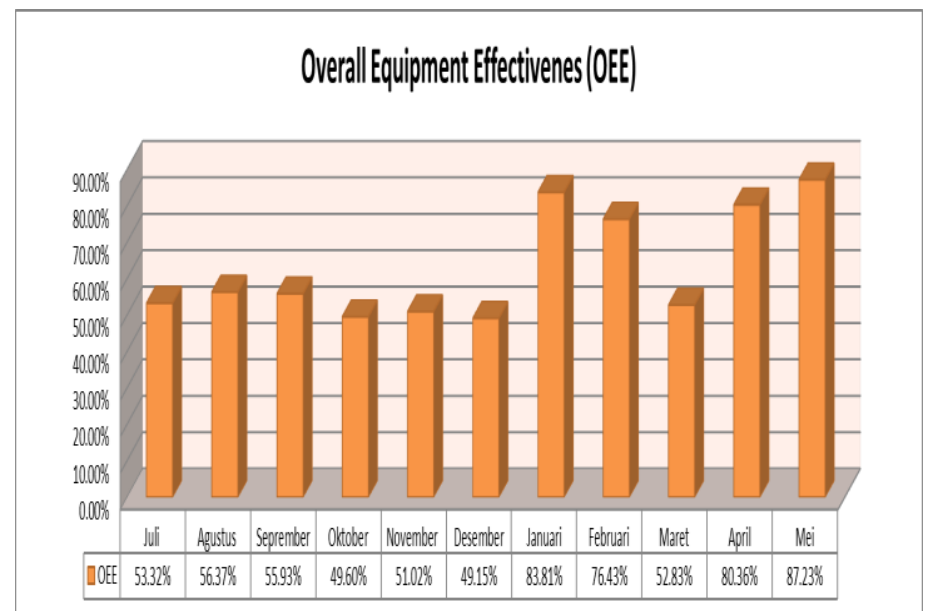

Gambar 4. Nilai Overall Equipment Effectivenes (OEE) Juli 2016 s/d Mei 2017

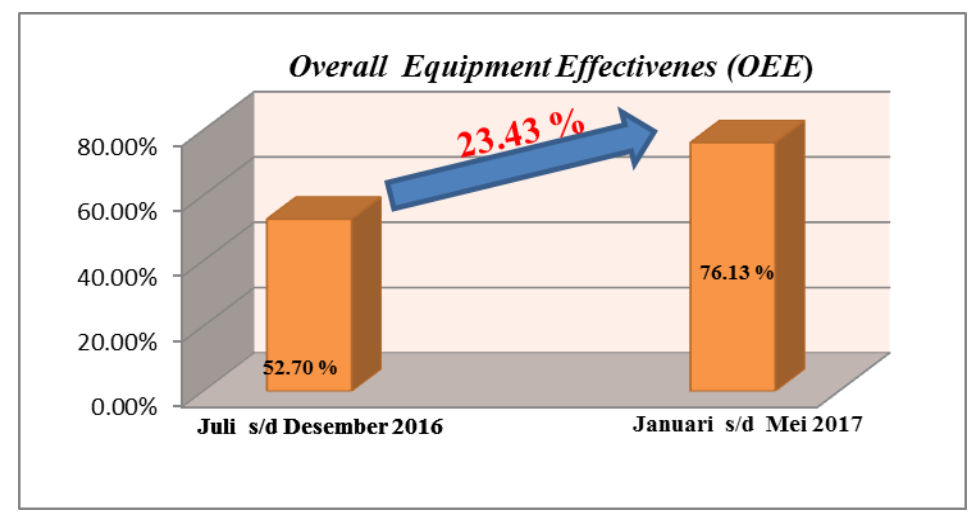

Gambar 5. Data Precentage Perbandingan Nilai Overall Equipment Effectivenes (OEE)

Maka dapat disimpulkan nilai rata-rata $O E E$ sebesar $76,13 \%$ pada bulan Januari sampai Mei 2017, bila dibandingkan dengan standar minimal yang di tetapkan PT Tansri Gani yaitu sebesar $>85 \%$, maka nilai overall equipment effectivenes $(O E E)$ yang didapat masih jauh dari nilai standar yang telah di tetapkan perusahaan. Akan tetapi nilai tersebut naik 23,43\% dari $52.70 \%$ pada periode bulan Juli sampai Desember 2016.

Maka penyebab terbesar rendahnya nilai overall equipment effectivenes (OEE) sesuai analisa nilai six big losses dengan menghitung losses tertinggi adalah Equipment Failure (kerugian akibat kerusakan peralatan). Rencana Tindakan Perbaikan Untuk Meningkatkan OEE, Untuk meningkatkan nilai OEE perlu usaha perbaikan secara continue, berikut ini disampaikan rencana tindakan untuk peningkatan OEE pada mesin KMF 250 A.

Tabel 7. Rencana Tindakan Perbaikan Untuk Meningkatkan OEE

\begin{tabular}{|c|c|}
\hline \multicolumn{1}{|c|}{ Permasalahan } & Tindakan \\
\hline Tidak adanya SOP dalam pemesanan sparepart mesin & $\begin{array}{c}\text { Dibuatkan SOP dan perencanaan pembelian sparepart mesin } \\
\text { sehingga stok sparepart dan perbaikan mesin tidak tertunda }\end{array}$ \\
\hline Pengecekan kondisi sparepart tidak sesuai jadwal & $\begin{array}{c}\text { Dibuatkan karyawan penanggung jawab dalam setiap jadwal } \\
\text { pengecekan serta lakukan pengawasan dalam setiap kegiatan } \\
\text { pengecekan }\end{array}$ \\
\hline Tempat penyimpanan material tidak sesuai standar & $\begin{array}{c}\text { Dibuatkan tempat yang sesuai standar dan perhatian khusus } \\
\text { dalampenyimpanan material sehingga material dalam kondisi } \\
\text { baik saat dibutuhkan untuk produksi }\end{array}$ \\
\hline Penggantian sparepart mesin menunggu rusak & $\begin{array}{c}\text { Melakukan pengecekan sparepart secara rutin dan dibuatkan } \\
\text { SOP dalampengecekan untuk mencegah kerusakan disaat } \\
\text { mesin saat produksi }\end{array}$ \\
\hline
\end{tabular}

JIM, Vol. 3, No. 1, Januari 2018, pp.29-36 


\section{KESIMPULAN}

Pada penelitian yang dilakukan di PT Tansri Gani periode Januari 2017 - Mei 2017 didapatkan nilai rata-rata availability $(88,39 \%)$, performance $(95,77 \%)$ dan quality $(89,43 \%)$. Nilai ketiga faktor tersebut menghasilkan nilai overall equipment effectivenes (OEE) mesin KMF 250 A sebesar $75,69 \%$, nilai tersebut masih dibawah dari standar yang ditetapkan perusahaan yaitu 85\%, akan tetapi nilai periode Januari 2017 - Mei 2017 naik 23,43\% dari periode Juli 206 Desember 2017 yang nilainya 52,70\%. Jadi efektivitas mesin KMF 250 A periode Januari 2017 Mei 2017 dinilai cukup baik walau belum mencapai target yang ditetapkan perusahaan. Perhitungan losses dilakukan untuk mengetahui kerugian yang mengakibatkan rendahnya nilai elemen OEE, hasil yang diperoleh dari keenam losses tersebut adalah equipment failure $(28,62 \%)$, setup and adjustment losses $(6.61 \%)$, idle and minor stoppage $(2,69 \%)$, reduced speed losses $(9,32 \%)$, defect losses $(7,57 \%)$, reduced yield $(0.16 \%)$. Jadi dari keenam nilai losses yang mempengaruhi rendahnya kinerja mesin KMF 250 A terdapat pada equipment failure $(28,62 \%)$ yang kerugian disebabkan oleh kerusakan peralatan.

\section{SARAN}

Dilakukan, maka disarankan perusahaan dapat melakukan perencanaan dalam melakukan pemesanan sparepart mesin guna menjaga ketersediaan sparepart mesin disaat mesin mengalami kerusakan. Karena dengan adanya perencanaan tidak akan terulang kehabisan sparepart yang mengganggu waktu perbaikan mesin, sehingga dapat meningkatkan nilai overall equipment effectivenes (OEE).

\section{DAFTAR PUSTAKA}

Ansori, Nachnul., \& Mustajib, M. Imron. 2013. Sistem Perawatan Terpadu (Integrated Maintenance System). Yogyakarta: Graha Ilmu.

Alvira, Dianra; Helianty, Yanti; Prassetiyo. 2015. Hendro. Usulan Peningkatan Efetivitas pada Mesin Tapping Manual Menggunakan Metode Overall Equipment Effectiveness (OEE). Jurnal Teknik Industri, Vol. 03 No. 03.

Gazperz, Vincent. 2012. All-in-One Management Toolbox, Cetakan Pertama. Bogor: Tri All Bros Publishing.

Kurniawan, Fajar. 2013. Manajemen Perawatan Industri. Yogyakarta: Graha Ilmu.

Nursanti, Ida. \& Susanto, Yoko. 2014. Analisi Perhitungan Overall Equipment Effectiveness (OEE) Pada Mesin Packing Untuk Meningkatkan Nilai Availability Mesin. Jurnal Imliah Teknik Industri, Vol. 13 No. 1.

Oktaria, Susanti. 2011. Perhitungan Dan Analisa Nilai Overall Equipment Effectiveness (OEE) Pada Proses Awal Pengolahan Kelapa Sawit. Program Studi Teknik Industri Universitas Indonesia, Depok.

Setiawan, Rudi Antonius. 2011. Analisi Dan Pengukuran Nilai Overall Equipment Effectiveness (OEE) Sebagai Dasar Perbaikan Proses Manufacture Line Injection Plastik Door Handle Mobil. Program Studi Teknik Industri.

Tannady, Hendy. 2015. Pengendalian Kualitas, Cetakan Pertama. Yogyakarta: Graha Ilmu. Universitas Indonesia, Depok. 
